\title{
Respiratory and Other Health Risks among Poultry- Farm Workers and Evaluation of Management Practices in Poultry Farms
}

\section{-Author(s)}

\section{Hamid $A^{\prime}$}

Ahmad AS

Khan $\mathrm{N}^{\prime}$

Kinnaird College for Women - Environmental Sciences.

\section{a Mail Address}

Corresponding author e-mail address Almas Hamid

Kinnaird College for Women - Environmental Sciences 93, Jail Road Lahore Lahore

Punjab - 54000 - Pakistan

Tel: $\quad+92423144071286$

\section{EKeywords}

Best management practices, FEV/FVC, Occupational hazards, Poultry farms. spirometry.

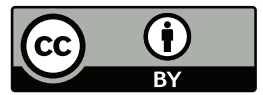

Submitted: 25/March/2017 Approved: 08/October/2017

\section{ABSTRACT}

The current study was conducted on eight poultry farms in Lahore and Sheikhupura to monitor environmental conditions, determine workers' health status and assess the implementation of standard management practices. Environmental monitoring, a health questionnaire survey and a respiratory function test were carried out. Seventy-one respondents were selected for the health assessment survey and lung function test. The results showed that the evaluated air-quality parameters, except for temperature and humidity, were well below the permissible occupational limits. Maximum temperature recorded was $32.75{ }^{\circ} \mathrm{C}$, while the highest humidity level was $85.5 \%$. Farms were shown to be compliant with standard guidelines and management practices. The workers' health survey indicated lower prevalence of work-related symptoms as compared to previous studies. However, most workers were not subjected to overall physical hazards, $21.1 \%$ of workers suffered from heat-induced dermatosis, and $38 \%$ suffered from heat exhaustion. Eye problems (watery, redness and itchiness) were experienced by $16.9 \%$ to $31 \%$. Reported respiratory symptoms included wheezing during colds $(18.3 \%)$, wheezing other than during colds $(1.4 \%)$, chest tightness $(16.9 \%)$, shortness of breath along with chest tightness (9.9\%), regular breathing difficulties (14.1\%), and coughing (15.5\%). Observed lung function pattern, as measured by FEV1/FVC ratio, was $87 \pm 17.7$, with $65 \%$ workers having 'restrictive' disorder and $21 \%$ normal lung function pattern, while $21 \%$ presented 'obstructive' lung function. The study concludes an overall better health and safety management in the selected poultry farms.

\section{INTRODUCTION}

The growing demand for economical and safe meat and egg supply has led to rapid development of the poultry industry. The emergence of industrial farming and the intensification of farm operations have promoted the growth of the poultry industry around the world, with China, Russia and India ranked among the top poultry-producing countries. With a total revenue of 564 billion Pakistani Rupees (PRs.) per year, Pakistan's poultry production industry ranks as the country's second largest organized and dynamic industry. This industrial sector has rapidly developed in the recent decades and is as source of direct and indirect employment opportunities to about 1.5 million people in the country. The potential of this sector can be gauged from the fact that its annual growth rate is between $8-10 \%$. Although $40 \%$ of the annual domestic meat consumption demand in Pakistan is supplied by commercial poultry farms, the sector still faces major challenges, which include lack of resources to manage poultry diseases, power shortages, increasing feed prices, and poor law and order situation in the country (Memon, 2012). 
Poultry farm businesses are associated with a number of local and regional environmental impacts. Poor manure management practices give rise to soil and water pollution. The use of pesticides and insecticides adversely affect the quality of nearby surface and ground water resources (Environmental, Health, and Safety Guidelines for Poultry Production, 2007). Odor emissions, due to release of gases including ammonia $\left(\mathrm{NH}_{3}\right)$ and hydrogen sulfide $\left(\mathrm{H}_{2} \mathrm{~S}\right)$, along with some volatile organic compounds (VOCs), significantly affect the environment and health of poultry workers (Donham et al., 2002). Confinement areas with high concentration of poultry or other livestock have been associated with frequent complaints of odor nuisance, which has been linked with health symptoms, including headache, irritation of eyes, nose and throat, and drowsiness (Hartung \& Schulz, 2011).

The main air pollutants - collectively referred as bio-aerosols - present in poultry production and hatcheries include poultry dust (mainly produced from microorganisms and their metabolites), pathogens, endotoxins, as well as $\mathrm{NH}_{3}$ and carbon dioxide $\left(\mathrm{CO}_{2}\right)$, as a consequence of excreta decomposition, respiration of poultry and other operations in the animal confinement buildings. These and others factors like manure, litter, feather, fragments and skin of animals are associated with adverse environmental and health impacts (Health and Safety Executive, 2009).

Epidemiological studies have shown that acute and chronic respiratory disease symptoms are prevalent in poultry-farm workers due to exposure to environmental conditions and live birds in confinement buildings. Hypersensitive lung diseases, such as extrinsic allergic alveolitis, and other acute respiratory symptoms (coughing, wheezing, and respiratory distress) have been associated with the inhalation of organic dust for prolonged exposure periods. Chronic respiratory disorders are also prevalent among poultry-farm workers, with 'ODTS (organic dust toxic syndrome)' and asthma being the most common. The type of health response depends on the level and frequency of exposure (Viegas et al., 2013). It is reported that $20 \%$ of the poultry-farm workers suffer from acute respiratory disorders, exhibiting symptoms such as wheezing, cough, phlegm, and sputum (Oppliger et al., 2008).

Physical hazards present in the work environment of poultry farms include heat stress, heat exhaustion, high noise levels, heat-induced dermatosis, high temperature and humidity in indoor confinement buildings. Chemical hazards result in acute and chronic respiratory diseases due to poultry dust exposure, skin and eye diseases due to the exposure to toxic gases originating from manure handling operations, immune diseases, and exposure to detergents, pesticides and disinfectants. Additionally, VOCs have also been detected in blood samples of poultry-farm workers (Jameel et al., 2015). The incidence of acute and chronic respiratory disorders such as wheezing, phlegm, congestion, dyspnea, upper respiratory tract irritation and other skin irritations in poultry-farm workers is mainly due to occupational exposure to chemical and biological hazards (May et al., 2012; Donham et al., 2000, 2000a).

Zoonotic diseases and infections (biological hazards) are transferred between animals and humans via different routes and infective agents, including bacteria, fungus, endotoxins, and viruses. Microbial inflammatory agents (such as endotoxins) have also been linked with a decrease in airflow and related respiratory symptoms. The (1/3)-beta-D-glucan present in the cell wall of fungi is another source of biological hazard. Its adverse health impacts involve suppression of the immune system and increase in the sensitivity to allergens (Ajetomobi et al., 2010). Other types of biological agents, including primary and opportunistic biological agents, are associated with the prevalence of multi-factorial environmental diseases. Some strains of microorganisms are capable of surviving in an airborne state for several minutes and can disperse in the vicinity of the poultry farm areas. A pertinent example is the mouth and foot virus, which can disperse to an aerial distance of $50 \mathrm{~km}$. Bacteria of the genus Staphylococcus, which are commonly present in animal production houses, has been found to occur about $500 \mathrm{~m}$ downwind of poultry barns at high concentrations of about $4000 \mathrm{cfu} / \mathrm{m}^{3}$ (LawniczekWalczyk et al., 2013).

Moreover, occupational hazards to which poultryfarm workers are exposed also include ergonomic factors that involve back pains, mainly due to wrong work postures and moving activities (Okiki et al., 2013). It has been demonstrated that farm management practices can have a profound impact on workers' health in numerous ways, while improved health and safety ( $\mathrm{H} \& \mathrm{~S}$ ) management in the farms is associated with lower incidences of workplace injuries and accidents (Autenrieth et al., 2016)

In view of the importance of the health and safety of poultry-farm workers, the current study was undertaken to identify the occupational hazards prevalent among poultry-farm workers, to determine their health status with key focus on respiratory health, to monitor environmental conditions, and to assess the implementation of standard management practices. 


\section{MATERIALS AND METHODS}

Eight (8) commercial poultry farms of Lahore and Sheikhupura, located in the province of Punjab of Pakistan, and a total of 71 poultry-farm workers were selected for this study. The following methodology was employed:

\section{Environmental Monitoring}

Air monitoring was performed twice: two separate readings, with a 10-min interval, were made during the work shift in each of the selected farms. The parameters monitored included total suspended particles (TSP), using a dust monitor (Micro dust Pro CEL-712a, Casella CEL, UK); ammonia $\left(\mathrm{NH}_{3}\right)$, using Drager tubes (X-am 5600, Drager, Lubeck, Germany); carbon monoxide (CO) level, using an air analyzer( IBRID MX6, iTXTM, Industrial Scientific, USA); noise level, using a digital sound level meter(850029, Sper Scientific, USA); and environmental temperature and humidity using a digital temperature and humidity clock meter (Model HTC-1, China).

\section{Questionnaire Survey}

A questionnaire was designed to analyze the $\mathrm{H} \& \mathrm{~S}$ hazards experienced by poultry-farm workers at study sites. The questionnaire was based on the standardized questionnaire of the American Thoracic Society, which is recommended for use in epidemiological surveys and literature on common H\&S hazards found in poultry production activities (Ferris, 1978). The questionnaire included basic demographic information, smoking status of workers, number of years of working in the selected areas, type of fuel used in homes, education status, and types of pesticides used on the poultry farm. With reference to hazards, the questionnaire contained four main sections related to physical, chemical, and biological hazards, as well as personal protection care. The chemical hazards section included questions on different health symptoms commonly experienced by poultry-farm workers, including fungal allergies, dust allergies, skin diseases, back pain, and respiratory disorder symptoms, including upper tract infections and allergies. Questions regarding current workers safety procedures practiced on the farms were also included.

\section{Respiratory Health Assessment}

Spirometry tests were performed to assess the lung function and respiratory health of poultry-farm workers by measuring the volume and flow of pulmonary inhalation and exhalation. The results of spirometry tests indicate normal, obstructive patterns, restrictive patterns, and a combination of both obstructive and restrictive patterns. The normal spirometry readings results vary with weight, height and age. The lung function test was carried out using a computer-based spirometry device (Blue Cherry, Geratherm Respiratory Spirometer Version 1.2.2.18, Germany), according to the standard spirometry procedures (Spirometry User Manual, 2014). The software records two tests: the SVC (slow vital capacity) test and the FVC (forced vital capacity) test. The predicted percentages, Forced Expiratory Volume in one second (FEV1) and FEV1/FVC ratio were measured.

Consent: Following the guidelines for such research, consent was obtained from workers. Participation of workers was voluntary and they were required to sign the consent form before undergoing lung function test and filling the questionnaire. Questionnaire filling and lung function test were conducted on site on each farm with the permission of the administration.

The research study was carried out after prior approval from the Human Ethical Committee of the Kinnaird College for Women.

\section{Assessment of the Implementation of Standard Management practices}

A checklist based on standard management practices and guidelines for poultry industry (EHS, 2007; Poultry Industry Good Practice Checklist, 2013) was designed to evaluate the implementation status of good management practices and to ensure the $\mathrm{H} \& \mathrm{~S}$ of poultry animals and workers.

\section{Statistical Analysis}

The data from the questionnaire survey was compiled and statistically analyzed using IBM SPSS version 20. The statistical tests applied were Pearson's chi-square test and Cramer's $\vee$ test.

\section{RESULTS AND DISCUSSION}

\section{Environmental monitoring}

The results of the environmental monitoring (Table 1) show that all the air quality parameters, except for temperature and humidity, were well below the permissible occupational limits set by the Occupational Safety and Health Administration (OSHA) and National Institute for Occupational Safety and Health (Donham et al., 2002). On all monitored farms, average dust concentrations, ranging from 0.662-1.564 mg/ $\mathrm{m}^{3}$, were lower than the standards, but higher than those reported in Europe, where the measured dust 


\section{Respiratory and Other Health Risks among Poultry- Farm Workers and Evaluation of Management Practices in Poultry Farms}

Table 1 - Environmental monitoring results (average levels) of air quality parameters

\begin{tabular}{|c|c|c|c|c|c|c|c|}
\hline & $\begin{array}{c}\text { TSP } \\
\left(\mathrm{mg} / \mathrm{m}^{3}\right)\end{array}$ & $\begin{array}{c}\text { CO } \\
(\mathrm{ppm})\end{array}$ & $\begin{array}{c}\mathrm{H}_{2} \mathrm{~S} \\
(\mathrm{ppm})\end{array}$ & $\begin{array}{c}\mathrm{NH}_{3} \\
\left(\mathrm{mg} / \mathrm{m}^{3}\right) \\
\end{array}$ & $\begin{array}{c}\text { Noise } \\
(\mathrm{dB})\end{array}$ & $\begin{array}{c}\text { Temperature } \\
\left({ }^{\circ} \mathrm{C}\right)\end{array}$ & $\begin{array}{c}\text { Humidity } \\
(\%)\end{array}$ \\
\hline Farm 1 & 0.952 & 9.5 & 2.15 & 1.4 & 78.5 & 30.25 & 81.5 \\
\hline Farm 2 & 0.826 & 8.5 & 1.85 & 1.45 & 79.5 & 31.1 & 80.5 \\
\hline Farm 3 & 0.662 & 8.5 & 1.95 & 1.3 & 80.6 & 32.75 & 78.5 \\
\hline Farm 4 & 0.779 & 8 & 2.15 & 1.55 & 78.9 & 31.75 & 70 \\
\hline Farm 5 & 0.688 & 8.5 & 2.25 & 1.35 & 80.8 & 30.75 & 78.5 \\
\hline Farm 6 & 1.202 & 8.5 & 2.25 & 1.5 & 80.8 & 31.25 & 78.5 \\
\hline Farm 7 & 1.564 & 8.5 & 1.95 & 1.25 & 81.5 & 28.95 & 86.5 \\
\hline Farm 8 & 1.028 & 8 & 2.0 & 1.65 & 81.4 & 28.90 & 79 \\
\hline OSHA & 10 (Grain dust) 15 (Nuisance dust) & 50 & 20 & 50 & 83 (12 hrs. TWA) & 25 & $20-60$ \\
\hline $\mathrm{NIOSH}$ & 4 (Grain dust) & 35 & 10 & 25 & 83 (12 hrs. TWA) & - & - \\
\hline
\end{tabular}

TSP: total suspended particulates, $\mathrm{CO}$ : carbon monoxide, $\mathrm{H} 2 \mathrm{~S}=$ =Hydrogen sulfide, NH3: Ammonia, TWA: time weighted average

$\mathrm{mg} / \mathrm{m3}$ : milligrams per cubic meter, ppm: parts per million, $\mathrm{dB}$ : decibels, ${ }^{\circ} \mathrm{C}$ : degrees centigrade, $\%$ : percentage

OSHA: Occupational Safety \& Health Administration,

NIOSH: National Institute for Occupational Safety and Health

concentration ranged between 0.19 and $0.64 \mathrm{mg} / \mathrm{m}^{3}$ for respirable dust, and between 2.4 and $13 \mathrm{mg} / \mathrm{m}^{3}$ for inspirable/inhalable dust samples. In another study, dust concentrations in poultry farms were between 0.02 to $81.33 \mathrm{mg} / \mathrm{m}^{3}$ (inhalable) and between 0.01 to $6.5 \mathrm{mg} / \mathrm{m}^{3}$ for respirable dust (Ellen et al., 2000). Although the poultry industry in North America does not report dust data, a number of studies did show the presence of endotoxins in dust samples (Reed et al., 2006).

The maximum recorded temperature $\left(32.75^{\circ} \mathrm{C}\right)$ and humidity $(85.5 \%)$ were relatively higher than the recommended limits, which may be due to the fact that the monitoring was conducted in the summer. As a consequence, the health survey indicated that $21.1 \%$ of the workers suffered from heat-induced dermatitis and 38\% suffered from heat exhaustion during the summer. However, according to the farm administration, the temperature and humidity of the poultry farms were monitored and maintained at the best level possible using ventilation fans and humidifiers to promote a favorable indoor temperature and humidity levels for the birds.

\section{Health assessment and spirometry results}

A total of 71 poultry-farm workers participated in the questionnaire survey for health assessment. All the interviewed workers worked for one shift of up to 12 hours. Table 2 summarizes the information acquired through questionnaire.

The duration of work experience was in the range of 1 month up to 7 years, with an average of 2 years. Most poultry-farm workers were young, with an average age of 25 years. Similar to present results, the study of Das et al. (2014) also reported similar job experience between $6-8$ years, with $1.72 \pm 0.965$ years. The statistical analysis (Chi-square and Cramer's $V$ tests) showed significant relationship between worker age and duration of work experience $(p<0.05)$.

Most workers attended school up to primary ( $5^{\text {th }}$ grade) and middle ( $8^{\text {th }}$ grade) grades. Most workers were non-smokers (60\%) as compared to smokers (32\%) and ex-smokers (7\%). Most workers (76\%) said they use wood as fuel for cooking and heating purposes at their homes due to the lack of availability of gas facilities in rural areas. However, no significant correlation ( $p>0.05)$ was found between fuel type used at home and workers' respiratory health.

The most common physical hazards experienced among poultry-farm workers include heat- and skininduced dermatosis, back pain due to over-exertion and wrong posture, and heat exhaustion during summer season (Guillam et al., 2013). Although in the studied areas, a large percentage of workers was not subjected to overall physical hazards mainly due to the efficient distribution of tasks among the workers, $21.1 \%$ of the workers suffered from heat-induced dermatosis and $38 \%$ suffered from heat exhaustion. These conditions may be linked to the shed temperature and humidity, which were higher than the permissible occupational standards, especially during summer.

The most common chemical and respiratory hazards identified include acute and chronic respiratory and ocular symptoms, such as wheezing, chest tightness episodes, shortness of breath, cough, phlegm, asthma, and eye itchiness and swelling (Guillam et al., 2013). However, in the present study, only a small percentage (7\%) of the workers suffered from some kind of chest illness that caused absenteeism. Most of the workers did not report any acute or chronic respiratory 
Table 2 - Summary of health symptoms experienced by poultry-farm workers

\begin{tabular}{|c|c|c|c|}
\hline \multirow[t]{5}{*}{ Physical hazards } & Health symptoms & Yes (\%) & No $(\%)$ \\
\hline & Heat-induced dermatosis & 21.8 & 78.9 \\
\hline & Skin-induced dermatosis & 21.8 & 78.9 \\
\hline & Heat exhaustion during summers & 38 & 62 \\
\hline & Back pain due to exertion or wrong posture & 38 & 62 \\
\hline \multirow[t]{14}{*}{ Chemical and respiratory hazards } & Chest illness during past three years causing absenteeism & 7 & 93 \\
\hline & Lung condition before the age of 16 & 0 & 100 \\
\hline & Wheezing in the chest -when suffering from cold/flu & 18.3 & 81.7 \\
\hline & Occasional wheezing in the chest, apart from colds & 1.4 & 98.6 \\
\hline & Experience of episodes of chest tightness & 16.9 & 83.1 \\
\hline & Experience of shortness of breath with chest tightness & 9.9 & 90.9 \\
\hline & $\begin{array}{l}\text { Describe your breathing: } \\
\text { Rarely has breathing difficulties } \\
\text { Regular breathing difficulties, but always completely recovers }\end{array}$ & $\begin{array}{l}85.9 \\
14.1\end{array}$ & $\begin{array}{l}14.1 \\
85.9\end{array}$ \\
\hline & Needs to stop for breath when walking at normal pace & 8.5 & 91.5 \\
\hline & Usually experiences coughing & 15.5 & 84.5 \\
\hline & Does not experience coughing while not working on the farm & 69 & 31 \\
\hline & Asthma & 1.4 & 98.6 \\
\hline & Watery eyes & 26.8 & 73.2 \\
\hline & Eye redness & 16.9 & 83.1 \\
\hline & Eye itchiness & 31 & 69 \\
\hline \multirow[t]{7}{*}{ Biological hazards } & Experienced hay fever anytime & 29.6 & 70.4 \\
\hline & Still has hay fever & 95 & 5 \\
\hline & Experiences any of the following infections during work on the poultry farm & & \\
\hline & Respiratory infection & 23.9 & 76.1 \\
\hline & Gastrointestinal infection & 2.8 & 97.2 \\
\hline & Skin infection & 7 & 93 \\
\hline & None & 66.2 & 33.8 \\
\hline
\end{tabular}

and ocular symptoms. The prevalence of respiratory symptoms experienced by the respondents included wheezing during colds (18.3\%), wheezing when not suffering colds (1.4\%), chest tightness (16.9\%), shortness of breath along with chest tightness (9.9\%), routinely experience breathing problems (14.1\%), and coughing (15.5\%). These symptoms were also reported as the most common complaints by Skorska et al. (2007) in a study on workers' health status in a hatchery with effective ventilation system. Viegas et al. (2013) also documented high incidence of respiratory signs in poultry-farm workers that did not have asthma, and included wheezing (19.1\%), sneezing, runny nose without flu or cold $(12.8 \%)$, coughing $(29.8 \%)$, and chest tightness (12.8\%).

In the present research, only $1.4 \%$ of the workers complained of asthma. As previously shown, the incidence of asthma does not seem to be increased in animal farmers mainly owing to the fact that farmers with asthma are inclined to quit this profession due to exacerbation of their symptoms (Reed et al., 2006). The incidence of asthma in male poultry farmers was reported to be as low as $1.2 \%$ in the study of Zuskin et al. (1995).
Eye conditions (watery eyes, and redness and itchiness) were experienced by 16.9 to $31 \%$ of the workers, which may be attributed to grain dust, as some people may be sensitized to dust, such that even low exposure levels may trigger eye and nasal irritation or worsen asthma (HSE, 2009).

The statistical analysis (Chi-square and Cramer's V tests) did not show any significant effect ( $p$ values $>$ 0.05) of the duration of work experience on different respiratory and ocular symptoms. This may be explained by the short duration of work experience of most of the workers, who therefore, were subjected to shorter time of exposure. Studies associate increased risk of respiratory hazards with the length of service, showing higher incidence of lung function decrement among workers with 10 or more years of exposure (Reed et al., 2006; HSE, 2009; Omland, 2002).

Likewise, most of the workers were not subjected to biological hazards (hay fever, colds and flu, other types of infections). Among the different types of infections evaluated, $23 \%$ of the workers experienced some kind of respiratory infection, indicating the prevalence of respiratory diseases. According to the survey, all workers used personal protective equipment 
(PPE), which included uniform kits (overalls, boots) and mask The mask was usually worn when antibiotics were sprayed, whereas the uniform kit was mandatory for all workers while working inside the sheds during the $12 \mathrm{hr}$ work shift. The efficient use of PPE plays an important role in reducing the prevalence of different hazards among poultry-farm workers.

Spirometry was performed to measure the lung function patterns of the respondents. The three important measures of spirometry used include FEV1 (exhalation volume of patient in the first second forced expiration), FVC (forced exhalation volume of patient), FEV1/FVC (the ratio of FEV1 to FVC expressed as a percentage) and VC (vital capacity).

The spirometry measurements and the observed lung function patterns indicate that the majority (65\%) of the workers had restrictive defects, $21 \%$ had normal lung function pattern, while $14 \%$ of the workers had obstructive defects. The mean observed values of FEV1, FEV1/FVC and FVC were $2.2 \pm 1.01,87 \pm 17.7$, and $3.67 \pm 1.09$, respectively, whereas the mean $\%$ predicted value of FEV1, FEV1/FVC and FVC were 57.8 $\pm 26.7,102.0 \pm 18.8$, and $79.6 \pm 22.7$, respectively. Mean \% predicted FEV1/FVC ratio values above $80 \%$ suggest the incidence of minimal obstructive lung function defect, while values below $80 \%$ indicate mild to severe pulmonary obstructive defects. In the study of Vegas et al. (2013), the absence of abnormal lung function in poultry-farm workers was observed.

The health survey results suggest better health profile of the workers of the modern poultry farms under study in comparison to those documented in the earlier studies in older poultry production facilities and hatcheries, with less effective ventilation (Skórska et al., 2007). However, most workers presented restrictive respiratory defects, indicating the prevalence of respiratory hazards in the poultry farm environment. In contrast, many previous studies have shown a significant decline in the lung function (Zuskin et al., 1995; Donham et al., 2000; Rylander et al., 2006), a high prevalence of chronic pulmonary disease (Simpson et al., 1998; Rylander et al., 2006), and common occurrence of work-related respiratory symptoms in poultry-farm workers (Zuskin et al., 1995; Simpson et al., 1998; Rees et al., 1998).

\section{Implementation of Standard Management practices}

The assessment regarding the adherence to best management practices indicated maximum compliance of the farms with standard guidelines and management practices. The checklist mainly included standard management methods and practices relative to feed manufacturing and storage, litter and manure management, ventilation methods and equipment, destocking, cleaning out practices, carcass handling, farm infrastructure, contingency management practices, indoor air quality management, and waste management. Based on the information collected, all farms received pre-processed feeds and had proper feed storage and distribution equipment. With respect to litter and manure management, drinking waterlines were monitored on daily basis to avoid leakages and litter caking, which cause odor emissions. In addition, manure belts were frequently emptied, and manure was dried on daily basis. It was observed that mostly absorbent bedding material (rice husk) was used, and additional litter was added accordingly on daily basis to avoid wet litter and litter caking, which are associated with ammonia production.

Six out of the eight studied poultry farms presented good housekeeping, which involved daily cleanliness check of the manure belts and pop holes. Five of the eight selected farms had separate system for waste water collection. All farms regularly emptied water tanks to prevent overflow. The doors were kept closed and ventilation was reduced during cleanout activities in order to control odor emissions. Only three farms carried out cleanout activities within one day of destocking, whereas these activities were performed within one week after destocking in the remaining farms. However, none of the farms took measures to avoid dust build-up in any place. All the selected farms had efficient temperature and humidity management systems, which included indoor temperature and humidity measurement devices, humidifiers, and ventilation fans. Ventilation matched the needs of the birds, and fan velocity was increased as needed, and was reduced during cleanout activities. Ventilation is considered as one of the key determinants of workers' respiratory health (Autenrieth et al., 2016).

Two farms did not present efficient carcass management, such as insufficient collection frequency and poor carcass storage location. As for used litter and manure management, the used litter was transferred to trucks in a contained area if not stored on site. Most of the farms had adequate incident-reporting systems. However, none of the farms had monitoring systems for decomposition gases, such as ammonia and carbon dioxide. Five of the farms presented adequate and regular maintenance of the sheds. Municipal solid waste management facilities were available in the area of the farms, except for two farms, which burnt waste on site. 


\section{CONCLUSION}

Although many epidemiological research studies have associated daily exposure to various pollutants in poultry production facilities with consequent impaired respiratory health of workers, production efficiency has improved in the recent years and it is considered highly significant for quality management. The present study showed that the monitored environmental air quality parameter values were well below the permissible occupational health limits. The health survey of the workers indicated lower prevalence of work-related symptoms compared with previous studies mainly due to the short period of employment and to the cleaner environment of modern poultry farms. Nonetheless, the spirometry tests showed that most of the poultry-farm workers presented restrictive lung defects, indicating the presence of respiratory hazards in poultry farms.

\section{CONFLICT OF INTEREST}

The authors declare that there is no conflict of interests regarding the publication of this manuscript.

\section{REFERENCES}

Ajetomobi J, Ajagbe F, Adewoye J. Occupational hazards and productivity of poultry farmers in Osun state of Nigeria. International Journal of Poultry Science 2010;9(4):330-333.

Autenrieth AD, Brazile JW, Douphrate ID, RománMuñiz NI, Reynolds JS. Comparing OHSMS programming with injury rates in poultry production. Journal of Agro Medicine 2016;21(4):364-372.

Das SR, Begum N, Biswas C, Hoq MN, Hossain J. Awareness about personal protective equipment and health problems among poultry workers. Northern International Medical College Journal 2014;5:336-338.

Donham KJ, Cumro D, Reynolds SJ, Merchant JA. Dose-response relationships between occupational aerosol exposures and cross-shift declines of lung function in poultry workers: recommendations for exposure limits. Journal of Occupational and Environmental Medicine 2000;42(3):260-269

Donham KJ, Cumro D, Reynolds S. Synergistic effects of dust and ammonia on the occupational health effects of poultry production workers. Journal of Agromedicine 2002a;8(2):57-76.

Donham KJ, Thorne PS, Breuer GM, Powers W, Marques S, Reynolds SJ. Exposure limits related to air quality and risk assessment. In: EHSRC, editor. lowa concentrated animal feeding operations air quality study. lowa: University of lowa College of Public Health;2002. p.164-183.

Ellen HH, Bottcher RW, von Wachenfelt E, Takay H. Dust levels and control methods in poultry houses. Journal of Agricultural Safety and Health $2000 ; 6: 275-282$

IFC - International Finance Corporation. Environmental, health, and safety guidelines for poultry production. Washington: World Bank Group; 2007

Ferris BG Epidemiology standardization project. II. Recommended respiratory disease questionnaires for use with adults and children in epidemiological research. American Review of Respiratory Diseases 1978;118:7-57

Guillam MT, Pedrono G, Le Bouquin S, Huneau A, Gaudon J, Leborgne $\mathrm{R}$, et al. Chronic respiratory symptoms of poultry farmers and model- based estimates of long-term dust exposure. Annals of Agricultural and Environmental Medicine 2013;20(2):307-311.

Hartung J, Schulz J. Occupational and environmental risks caused by bioaerosols in and from farm animal houses. Agricultural Engineering International: the CIGR Journal 2011;13(2):1-8

HSE - Health and Safety Executive. Statement of evidence respiratory hazards of poultry dust. 2009. Available from: http://www.hse.gov.uk/ pubns/web40.pdf

Jameel U, Batool A, Hayat TM. Assessment of occupational exposure to volatile organic compounds in poultry workers. International Journal of Research in Applied, Natural and Social Sciences 2015;3(2):59-68.

Lawniczek-Walczyk A, Gorny RL, Golofit-Szymczak M, Niesler A, Wlazlo A. Occupational exposure to airborne microorganisms, endotoxins and $\beta$-glucans in poultry houses at different stages of the production cycle. Annals of Agricultural and Environmental Medicine 2013;20(2):259 268.

May S, Romberger DJ, Poole JA. Respiratory health effects of large animal farming environments. Journal of Toxicology and Environmental Health, Part B $2012 ; 15(8): 524-41$.

Memon N. Poultry: country's second-largest industry. 2012. Available from: https://www.foodjournal.pk/Nov-Dec-2012/Nov-Dec-2012-PDF/ Exclusive-article-Dr-Noor.pdf.

Okiki AP, Ogbimi OA, Edafiadhe EW. Effects of air-borne hazards on the physical and psychological health of nigerian poultry workers. Journal of Biology, Agriculture and Healthcare 2013;3(7):102-110.

Omland $\mathrm{O}$. Exposure and respiratory health in farming in temperate zones - a review of the literature. Annals of Agricultural and Environmental Medicine 2002;9(2):119-136

Oppliger A, Charriere N, Droz P, Rinsoz T. Exposure to bioaerosols in poultry houses at different stages of fattening; use of real-time pcr for airborne bacterial quantification. Annals of Occupational Hygiene 2008;52(5):405-412.

Poultry industry good practice checklist: reducing odours from poultry production through the application of best. 2013. Available from: http://legacy.iica.int/Esp/regiones/sur/uruguay/Documentos $\% 20$ de $\% 201$ \% $\% 200$ ficina/CursoBPPPA/Literatura/Best \%20Practices \%20 Odor.pdf

Reed S, Quartararo M, Kift R, Davidson M, Mulley R. Respiratory illness in farmers dust and bioaerosols exposures in animal handling facilities [publication 06/107]. Australia: RIRDC Project; 2006.

Rees D, Nelson G, Kielkowski D, Wasserfall C, Da Costa A. Respiratory health and immunological profile of poultry workers. South African Medical Journal-Cape Town-Medical Association of South Africa 1998;88:1110-6.

Rylander R, Carvalheiro MF. Airways inflammation among workers in poultry houses. International Archives of Occupational and Environmental Health 2006;79(6):487-90.

Simpson JC, Niven RM, Pickering CA, Fletcher AM, Oldham LA, Francis $\mathrm{HM}$. Prevalence and predictors of work related respiratory symptoms in workers exposed to organic dusts. Occupational and Environmental Medicine 1998;55:668-672

Skórska C, Mackiewicz B, Golec M, Cholewa G, Chmielowiec-Korzeniowska A, Dutkiewicz J. Health effects of exposure to organic dust in workers of a modern hatchery. Annals of Agricultural and Environmental Medicine 2007:14:341-345

Spirometry user manual version 1.2.2. Geschwenda: Geratherm Repiratory; 2014

Viegas S, Faísca V , Dias $\mathrm{H}$, Clérigo A, Carolino E, Viegas C. Occupational exposure to poultry dust and effects on the respiratory system in workers. Journal of Toxicology and Environmental Health, Part A 2013;76(4-5):230-239.

Zuskin E, Mustajbegovic J, Schachter EN, Kern J, Rienzi N, Goswami $S$, et al. Respiratory function in poultry workers and pharmacologic characterization of poultry dust extract. Environmental Research 1995;70:11-19 
